\title{
New prevalence surveillance of Toxoplasma gondii among rodents and stray cats by ELISA avidity and nested PCR methods, Northeast of Iran
}

\author{
Ehsan Shariat Bahadori $^{1} \cdot$ Javid Sadraei $^{1} \cdot$ Abdolhosein Dalimi $^{1}$
}

Received: 12 December 2018/Accepted: 18 February 2019/Published online: 28 February 2019

(C) Indian Society for Parasitology 2019

\begin{abstract}
Rodents and stray cats are the sources of many parasitic infections including $T$. gondii, for other animals and human. Toxoplasmosis has a wide range of laboratory factors in its intermediate and definite hosts. Regarding the importance of rodents and stray cats as the hosts that spread the Toxoplasma gondii, it is necessary to obtain comprehensive information about these animals in the life cycle of T. gondii. The objective was to investigate the new prevalence of toxoplasmosis among target animals in Iran, using GRA6 gene in combinacion with ELISA avidity. In this study, 286 rodents and 210 stray cats were collected and their heart tissues extracted to obtain DNA, blood samples and $\operatorname{IgG} \mathrm{Ab}$ of T.gondii parasite. We detected the positive tissue samples in our study by the nested-PCR method. Then, we examined T. gondii IgG ELISA avidity for assessment of toxoplasmosis among rodents and stray cats. This study, was conducted in January to March 2017, based on the prevalence study. The findings revealed that $246 / 286(86.01 \%)$ of rodents and $180 / 210(85.71 \%)$ of stray cats were positive by IgG ELISA avidity methods. moreover, 68 rodents samples and 38 stray cats samples were positive concerning the GRA6 Toxoplasma gene; and these positive samples were at intermediate levels for IgG avidity. We concluded that the new prevalence of toxoplasmosis among rodents and stray cats was at high levels,
\end{abstract}

Javid Sadraei

sadraeij@modares.ac.ir

Ehsan Shariat Bahadori

e.shariat@modares.ac.ir

Abdolhosein Dalimi

dalimi_a@modares.ac.ir

1 Department of Parasitology, Faculty of Medical Sciences, Tarbiat Modares University, Tehran, Iran using the serologic method in Northeast of Iran and the results of quantitative ELISA avidity were as the same as those of the nested-PCR for detecting recent toxoplasmosis in these hosts.

Keywords Toxoplasmosis - New prevalence · Iran · Molecular detection · Serology study

\section{Introduction}

T. gondii is an important coccidian with worldwide distribution, which causes a serious disease, toxoplasmosis, in human and animals. The stray and feral cat's definitive hosts can just excrete million oocysts by their feces. Cysts can remain infective for many months in sultry climates and spread in the environment or anything mixed with the feces. Stray cats can be infected by ingesting tissue cyst from intermediate hosts, such as wild rodents (Verma et al. 2018; Wang et al. 2018c).

There are a lot of tests for detecting positive infection with $T$. gondii including ELISA, indirect hem agglutination assay (IHA), ELISA Avidity and PCR for different genes. The LAT, ELISA and ELISA avidity are currently applicable for serological diagnosis of the infection; however the ELISA avidity with $97 \%$ sensitivity is a highly userfriendly method to detect toxoplasmosis infection (Hecker et al. 2018; Hou et al. 2018; Oh et al. 2018).

The aim of this study was to investigate the new prevalence of T. gondii among rodents and stray cats using ELISA avidity and PCR methods in Northeast of Iran. This investigation was necessary to assess the prevalence of Toxoplasmosis, using both serological and molecular methods. 


\section{Materials and methods}

\section{Study area}

Golestan province is the main reservoir of the rodents and stray cats as toxoplasmosis circulating agents. The region is located next to the Caspian Sea, and has very sultry and rainy climate. This study was performed in 2017.

\section{Sampling}

We collected 286 heart tissues and blood samples of rodents and 210 heart tissues and blood samples of stray cats simultaneously from Golestan forest, where rodents and stray cats live. The samples were collected using intravenous blood sampling with syringe; then the animals were killed to isolate their heart tissues. The samples were transferred to a laboratory to examine nested-PCR, using GRA6 gene for detecting toxoplasmosis. Finally, IgG avidity was assessed in serum samples of the infected hosts, using the ELISA avidity method for evaluation of the infection time. The study was based on the prevalence and randomized abundance analysis. Tissue sample examination, processing and lysis were conducted before DNA extraction and nested-PCR.

Animal species were Rattus Rattus, Rattus norvegicus, Mus musculus, Rombomys opimus and stray cat.

\section{DNA extraction}

Extraction of genomic DNA was conducted using sodium $\mathrm{DNG} /$ proteinase $\mathrm{K}$ method. The material was purchased from Sinacolon Company and eluted into $50 \hat{A} \mu 1 \mathrm{DDH} 2 \mathrm{O}$, according to the manufacturer's instructions. A nestedPCR for T. gondii GRA6 gene was applied to confirm probable infection.

We cut $3 \mathrm{~g}$ of the sample tissue into small pieces and put them in a $1.5 \mathrm{ml}$ sterile tube. $180 \mu \mathrm{l}$ lyse buffer was added for homogenization and $400 \hat{A} \mu 1$ DNG solution was also added and homogenized once again; then, $20 \mu$ proteinase $\mathrm{K}$ was added.

We mixed them immediately by shaking for $20 \mathrm{~s}$ and incubated at $60{ }^{\circ} \mathrm{C}$ for $1 \mathrm{~h}$ to lyse the sample. If tissue resists to lysing, the incubation time would increase to 2-3 h. The samples were shacked or inverted in 10-15 min intervals. Then, we added $300 \hat{A} \mu 1$ Isopropanol to DNA precipitation. After 5-10 min the tubes were washed by $70 \%$ ethanol. Finally, we eluted the DNA by deionized $\mathrm{H}_{2} \mathrm{O}$. The eluted DNA was preserved at $-20{ }^{\circ} \mathrm{C}$ using a nested-PCR method for detection of infection. The positive control sample in this study was Tehran strain of $T$. gondii.
The PCR kit was purchased from the Pishgam CompanyIran.

\section{Nested-PCR analysis for T. gondii GRA6 gene}

Nested-PCR analysis was performed to detect Toxoplas-ma GRA6 gene as a diagnostic gene. The primers were designed according to Pishgam Corporation (Table 1).

Amplification of the GRA6 gene was completed in a 5-min cycle at $95^{\circ} \mathrm{C}$ for initial denaturation, followed by 30 one-min cycles at $95{ }^{\circ} \mathrm{C}, 1 \mathrm{~min}$ at $62^{\circ} \mathrm{C}$, and $3 \mathrm{~min}$ at $74{ }^{\circ} \mathrm{C}$. The best annealing temperature for PCR 1 was $58{ }^{\circ} \mathrm{C}$ and for PCR 2 was $57.5^{\circ} \mathrm{C}$.The segment lengths were 546 bp in PCR1 and 344 bp in PCR2 (Table 2). The reason for choosing this gene was generalization of this molecular marker in various strains of T. Gondii and this gene was used in many studies.

Then, we evaluated the serum of the infected rodents and stray cats to detect IgG avidity, using tachyzoite enzyme-linked immune assay method.

\section{Tachyzoite based ELISA avidity test}

ELISA avidity test has been used for detection of the Toxoplasma IgG in blood serum of the rodents and stray cats, according to the Euro immune ELISA avidity kit with specific conjugation. The positive control in the avidity ELISA test was embedded in the commercial kit. The ELISA avidity procedure was performed using Euro Immune Kit-France, according to manufacturer's instructions.

The formula of ELISA avidity (semi quantitative):

OD patients (serum samples)

OD calibrator 2

The result $>1.1$ represents positive toxoplasmosis.

The formula of quantitative ELISA avidity (qIgG):

OD (serum samples) in urea buffer

OD (serum samples) in phosphate buffer

The result $\times 100=$ RIA (relative index avidity); the RIA value below $40 \%$ is in low avidity, between 40 and $60 \%$ is in intermediate avidity and oer $60 \%$ is in high avidity.

\section{Statistical analysis}

In this study, one-sample and two-sample t-tests, correlation table, frequency charts, high-low diagram and SPSS 19 software were used for data analysis. IgGq was nearly equal to the quantitative IgG ELISA avidity. 
Table 1 Primer sequences

\begin{tabular}{llll}
\hline PCR & Segment length & Primer sequences & Annealing temperature \\
\hline Primary & 546 & Forward: $5^{\prime}$-ATTTGTGTTTCCGAGCAGGT-3' & $58{ }^{\circ} \mathrm{C}$ \\
& & Reverse: $5^{\prime}$-GCAC & \\
& CTTCGCTTGTGGTT-3' & $57.5^{\circ} \mathrm{C}$ \\
Secondary & 344 & Forward: $5^{\prime}$-TTTCCGAGCAGGTGACCT-3' & \\
& & Reverse: $5^{\prime}$-TCGCCGAAGAGTTGACATAG-3 & \\
\hline
\end{tabular}

$q$ quantitative

Table 2 PCR substrate

\begin{tabular}{lll}
\hline Materials & Volume $(\mu \mathrm{l})$ & Final concentration \\
\hline Master Mix & 7.5 & $2 \mathrm{X}$ \\
DNA Sample & 2 & $10-100 \mathrm{ng} / \mu \mathrm{l}$ \\
Work Primer & 1 & 20 Picomol \\
Distilled water & 4.5 & - \\
Total & 15.0 & - \\
\hline
\end{tabular}

\section{Results}

In this study, $246 / 286(86.01 \%)$ of rodents and 180/210 $(85.71 \%)$ of stray cats were positive based on the Toxoplasma IgG ELISA avidity method. It was also found that 68 rodent samples and 38 stray cat samples were positive in presence of GRA6 gene. In rodents, 38 samples were Ratus ratus, 10 samples were Ratus norvegicus, 10 samples were Mus musculus and 10 samples were Rombumys opiums. These samples were positive in 344 bp location. The primer designing was conducted using BLAST softwareNCBI site. Among 131 Rattus Rattus samples, 38 were positive (29\%), among 45 Rattus norvegicus samples, 10 were positives (22\%), among 60 Mus musculus samples, 10 were positive (16\%), among 50 Rombomys opimus samples, 10 were positive (20\%) and finally among 210 stray cat's samples,38 were positive (18\%) (Fig. 1).

In this survey, we analyzed the prevalence study to show the important correlation between Toxoplasma PCR results
(68/286 samples of rodents and 38/210 samples of stray cats) and positivity of Toxoplasma IgG ELISA Avidity (246/286 samples of rodents and 180/210 samples of stray cats). However, we found that 246/286 (86.01\%) of rodents and $180 / 210(85.71 \%)$ of stray cats were positive, using $\operatorname{IgG}$ ELISA avidity method but just $68 / 286$ of the rodents and $38 / 210$ of the stray cats showed positive band in $344 \mathrm{bp}$ location of GRA6 gene, using the nested PCR method.

Tables 3 and 4 show the $t$ test results, and analysis of the infected rodents and stray cats to compare serum levels of semi quantitative $\operatorname{IgG}$ and quantitative $\operatorname{IgG}(\mathrm{IgGq})$, with 95\% confidence interval. Figure 2 shows the frequency histogram tables of the serum level of Toxoplasma IgG avidity among the rodents and stray cats. The results were 2-2.5 (toxoplasmosis positive) among 246/286 rodents and 180/210 stray cats, with $95 \%$ confidence interval. Figure 3 shows the frequency histogram tables of the serum levels of Toxoplasma IgG quantitative avidity among the rodents and stray cats. The results were about 30\% with $95 \%$ confidence interval, respectively. In this study, we showed that Toxoplasma GRA6 gene was detected only in rodents and stray cats with Toxoplasma intermediate ELISA avidity (40-60\% relative index avidity).

Figure 4 shows the high/low bars of Toxoplasma IgG and $\mathrm{IgGq}$ (quantitative) positive rodents and stray cats. The results of $\operatorname{IgG}$ avidity were in $2-2.5$ (semi quantitative ELISA) among these animals with $95 \%$ confidence interval. These results were in about $30 \%$ among $68 / 286$ rodents and 38/210 stray cats (quantitative ELISA) with 95\%

Fig. 1 Nested-PCR result using GRA6 gene

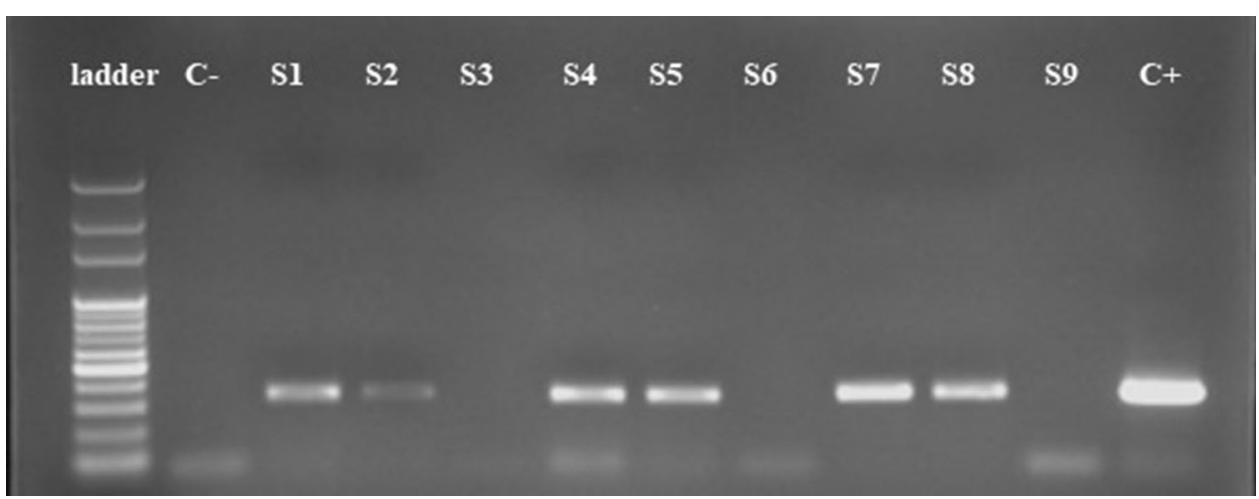


Table 3 One-sample statistics

\begin{tabular}{llccc}
\hline & $\mathrm{N}$ & Mean & SD & SE Mean \\
\hline IgG rodent & 286 & 2.2067 & 1.09861 & 0.06496 \\
IgG stray cat & 210 & 2.3042 & 1.10651 & 0.07636 \\
IgGq Rodent & 286 & 31.4301 & 11.31496 & 0.66907 \\
IgGq Stray cat & 210 & 31.0095 & 11.82366 & 0.81591 \\
\hline
\end{tabular}

$q$ quantitative

Table 4 One-sample t-test

\begin{tabular}{llllllc}
\hline & \multicolumn{2}{l}{ Test value $=0$} & & \\
\cline { 2 - 6 } & $t$ & $d f$ & Sig. (2-tailed) & Mean difference & \multicolumn{2}{c}{$95 \%$ confidence interval of the difference } \\
\cline { 3 - 6 } & & & & & Lower & Upper \\
\hline IgG rodent & 33.969 & 285 & .000 & 2.20671 & 2.0788 & 2.3346 \\
IgG stray cat & 30.177 & 209 & .000 & 2.30419 & 30.1131 & 32.74770 \\
IgGq Rodent & 46.976 & 285 & .000 & 31.43007 & 29.4011 & 32.6180 \\
IgGq Stray cat & 38.006 & 209 & .000 & 31.00952 & & \\
\hline
\end{tabular}

$q$ quantitative
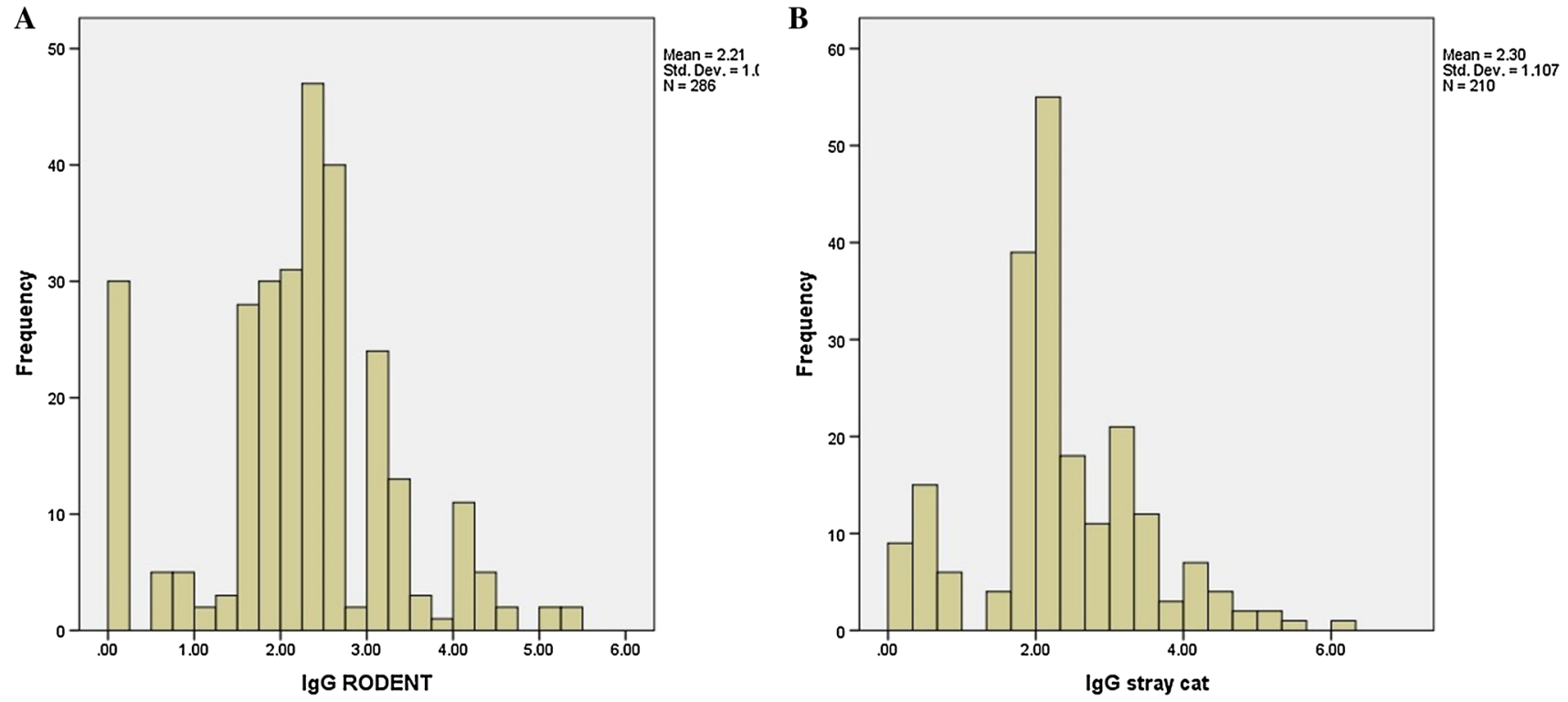

Fig. 2 a and b Histogram table of Toxoplasma $\mathrm{IgG}$ avidity in rodents and stray cats

confidence interval. Table 5 shows the comprehensive data achieved through analysis of Toxoplasma $\mathrm{IgG}$ and $\mathrm{IgGq}$ rodents and stray cats. According to this table, the mean of Toxoplasma IgG was in 2.20 for rodents and 2.30 for stray cats or the mean of Toxoplasma IgG q (quantitative) was 31.43 among the rodents and 31.01 among the stray cats. The proved intermediate avidity in these infected hosts and the SD of Toxoplasma IgG was 1.099 among the rodents and 1.10 among the stray cats. In addition, the SD of
Toxoplasma IgGq (quantitative) was 11.31 among the rodents and 11.82 among the stray cats. Evaluating the prevalence analysis of the two methods for detecting toxoplasmosis in Northeast of Iran revealed a statistical significance. The results of nested-PCR were just applied for approving the existence of parasite, also semi quantitative ELISA avidity detected the presence of IgG antibody; however quantitative ELISA avidity method was used to evaluate the acuteness of the infection. In this study, we 

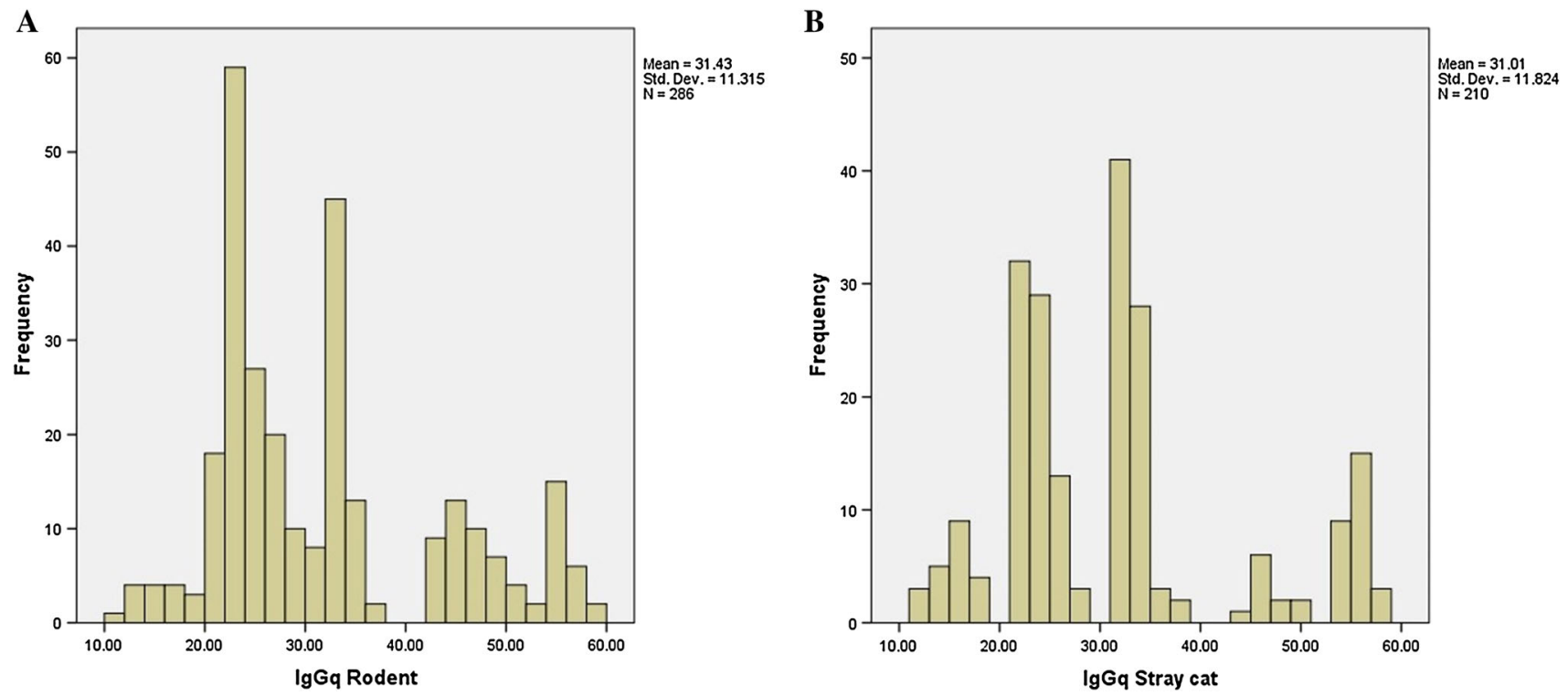

Fig. 3 a and b Histogram table of Toxoplasma IgGq avidity in rodents and stray cats

A

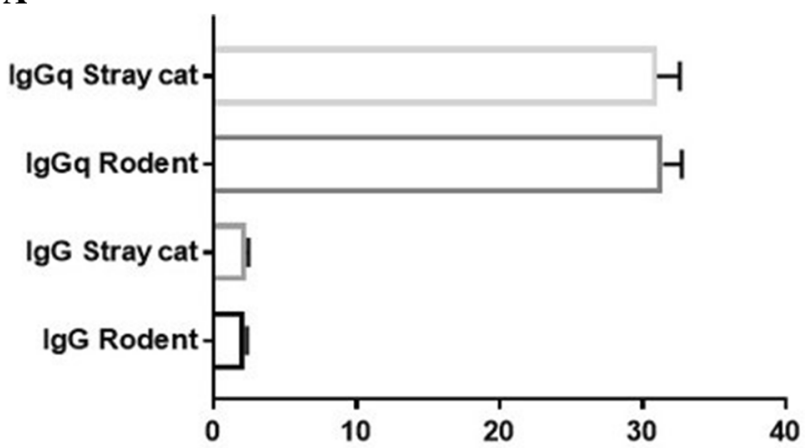

B

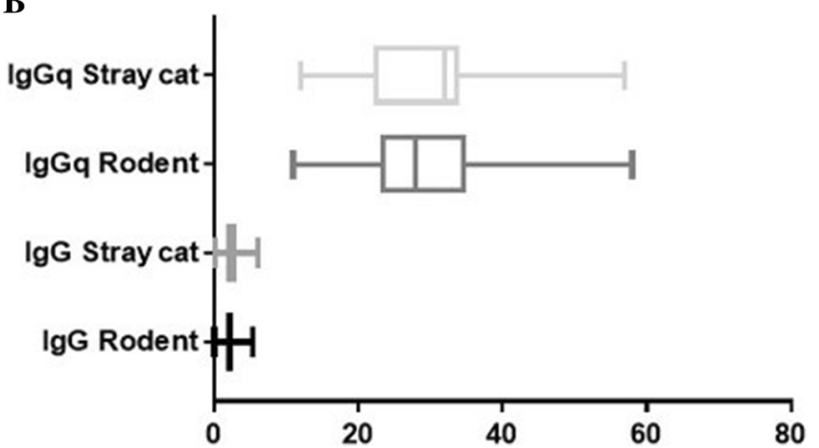

Fig. 4 a and b High low bars of Toxoplasma $\operatorname{IgG}$ and IgGq avidity in rodents and stray cats. $S$ sample, $C$ control, $q$ quantitative

found that these animals with Toxoplasma GRA6 gene had acute infection, based on the quantitative ELISA avidity, but the hosts with chronic infection reported negative for Toxoplasma GRA6 gene. It means that GRA6 gene was detected only in quantitative ELISA avidity positive animals.

\section{Discussion}

One of the main difficulties of this study was simultaneous sampling of the rodents and stray cats. Golestan province located in Northeast of Iran with a sultry climate. In this study, the serologic and molecular methods have been used simultaneously for the first time to test the serum and tissue samples of the rodents and stray cats in the Golestan province. The results of this study revealed that the prevalence of toxoplasmosis with ELISA avidity procedure was higher than that in the polymerase chain reaction method in Northeast of Iran. Golestan province is the main reservoir of the rodents and stray cats as disseminators of toxoplasmosis. Rodents are the main reservoir host for toxoplasmosis that infects stray cats. Climate characteristic of region is highly suitable for toxoplasmosis. Many studies have been conducted on the occurrence of $T$. gondii among the cats and rodents in Iran. Sharif et al. 2009 have reported prevalence of forty percent $T$. gondii antibodies among the stray cats in Sari, Northern Iran. They conducted $T$. gondii antibodies test with latex agglutination on 100 serum samples collected from stray cats in five urban areas of Sari. Mostafavi et al. detected the differences in T. gondii infection between the male and female stray cats. Khademvatan et al. 2013 showed the existence of birds toxoplasmosis in Southwest of Iran (Mostafavi and Jalali Monfared 2012).

In recent years, there were no study to detect rodent and stray cat's toxoplasmosis in Golestan area. The present study showed the important role of the rodents and stray cats in dissemination of toxoplasmosis in sultry areas. It also revealed that the GRA6 gene was a critical marker to 
Table 5 Data analyze of Toxoplasma $\operatorname{IgG}$ and IgG quantitative avidity rodents and stray cats

\begin{tabular}{lllll}
\hline & IgG rodent & IgG Stray cat & IgGq Rodent & IgGq Stray cat \\
\hline Number of values & 286 & 210 & 286 & 210 \\
Minimum & 0.02 & 0.18 & 11 & 12 \\
25\% Percentile & 1.7 & 1.775 & 23 & 22 \\
Median & 2.3 & 2.1 & 28 & 32 \\
$75 \%$ Percentile & 2.625 & 3.025 & 35 & 34 \\
Maximum & 5.4 & 6.1 & 58 & 57 \\
Mean & 2.207 & 2.304 & 31.43 & 31.01 \\
SD & 1.099 & 1.107 & 11.31 & 11.82 \\
SE Mean & 0.06496 & 0.07636 & 0.6691 & 30.11 \\
Lower 95\% CI of mean & 2.079 & 2.154 & 32.75 & 29.4 \\
Upper 95\% CI of mean & 2.335 & 2.455 & 8989 & 32.62 \\
Sum & 631.1 & 483.9 & 6512 \\
\hline
\end{tabular}

$q$ quantitative

detect the abundance of toxoplasmosis and that the heart tissue was one of the main tissues to follow up GRA6 gene from Toxoplasma parasite. Moreover, the rodents and stray cats were important agents of spreading toxoplasmosis in the region. The parasite forms tissue cysts with bradyzoites in various tissues (also in heart tissue), so the detected parasitic DNA (GRA6 gene) comes from bradyzoites more probably than from tachyzoites. The result of the recent studies revealed that toxoplasmosis among the rodents and stray cats of the Golestan province is about $85 \%$. Regarding the climate of the Golestan province, which is theoretically highly suitable for $T$. gondii growth, detection of high rate of seropositive samples is probable. T. gondii parasite is responsible for toxoplasmosis as one of the most important diseases that causes ecological problems in rodents and stray cats' environment. Serological test can be applied as an important instrument to diagnose the infection among the herds. This test detects specific anti-T.gondii antibodies, and involves techniques such as indirect fluorescence antibody test (IFAT), toxoplasma agglutination test (TAT), enzyme-linked immunosorbent assay (ELISA), rapid immune chromatographic test (RIT), and the immunoblot assay. T.gondii is an inevitable intracellular coccidian parasite and an important zoonotic pathogen that causes severe diseases in congenitally infected rodents and strays cats and in immune-compromised patients. Rodents and stray cats are the main reservoir for toxoplasmosis in Northeast of Iran. Early detection of the toxoplasmosis is very important to follow up the disease. The intrinsic factors of oocyst dispersal from the initial Drop-off locations of the infected feces may also be a crucial factor contributing to the widespread distribution of oocysts in soil. Antibodies to T.gondii was found in the cat, in 5/28 black rats (18\%), and 2/18 brown rats, from Brazil (11\%)(Silva et al. 2017; Simon et al. 2017).

In these hosts, the incidence of transmission elevates thereafter to more than $90 \%$, when congenital infection occurs during the late weeks before delivery, which is more likely to be asymptomatic, yet may proceed to neurologic disorders later in childhood or in adolescence. One-third of the mother rodents, who acquire a primary T.gondii infection during pregnancy, transmit the infection to their fetuses and disseminate the infection to the environment (Bastien et al. 2018; Brouat et al. 2018; Foronda et al. 2015; Gennari et al. 2015; Mikhail et al. 2017; Normaznah et al. 2015; Wang et al. 2018d).

One of the reasons for using ELISA avidity method in rodents and stray cat's studies was to find out the proper time for the host to be tested for Toxoplasma parasites, because finding this time and that the host is at what stage of infection are efficient in the severity of the infection. The Rodents were divided into four groups and stray cats in our study included in the group with the total hosts involved with Toxoplasma parasites. According to the results of this study, 246/286 rodents and 180/210 stray cats developed positive antibodies. Moreover, the results revealed that there were 68 positive $T$. gondii GRA6 gene rodents and 38 positive $T$. gondii GRA6 gene cats among the samples. Rodents and cats cannot develop positive antibodies and more probably ELISA test can be positive because of the presence of antibodies against T.gondii in the serum of the infected animals. Prevention and treatment of this parasitic infection in animals is not common, even if they are diagnosed in the early acute stage. The preventive measures are only used to avoid infection in domestic animals and human.Toxoplasmosis of rodents and stray cats may not create environmental and health problems for 
human, in Northeast of Iran. Despite the efforts of veterinarians to eradicate this disease in northeastern Iran, the infection remains as one of the unresolved problems. In Golestan region, especially in its tourism areas, people are in contact with these animals, and in rare cases, they can lead to severe infections or even epidemics. Early detection of the toxoplasmosis in these animals can be helpful to prevent the spread of infection to human and other hosts. A simple ELISA method used in toxoplasmosis analysis detects presence of the antibodies in these hosts. The molecular method is positively associated with the ELISA avidity method and can contribute to the health of the region (Jung et al. 2017; Must et al. 2017; Pena et al. 2017; Wang et al. 2018a, b, d; Wang et al. 2017).

Prevention of the congenital toxoplasmosis in rodents and stray cats has been based mainly on serological tests for anti-Toxoplasma antibodies. Many serological tests, including the ELISA and ELISA avidity methods have been used to detect the antibodies against T.gondii (Flegr 2017; Liang et al. 2016; Macaluso et al. 2018; Poulle et al. 2016; Spada et al. 2012; Teimouri et al. 2018). However, infection should be diagnosed at the early acute stages, when treatment is more effective. Therefore, the ELISA avidity method is useful in detection of the congenital toxoplasmosis among the rodents and stray cats and its results will be reliable, if we use the designed ELISA avidity kit from Toxoplasma ES antigens (tachyzoite based ELISA avidity) (Ahmadpour et al. 2017; Felin et al. 2017; Naghili et al. 2017; Patel et al. 2017; Pishkari et al. 2017).Toxoplasmosis is not critical disease in Iran but it is necessary to prevent it from spreading animals to humans.

\section{Conclusion}

According to the results of this study, the Northeast of Iran is a very important region for following up the toxoplasmosis infection, specifically among the animals such as rodents and stray cats (their main reservoir is Golestan). Moreover, quantitative $\mathrm{IgG}$ avidity ( $\mathrm{qIgG}$ ) results were at the intermediate level among the rodents and stray cats with T.gondii GRA6 positive gene in the region. We also concluded that the prevalence rate of toxoplasmosis in serology study was higher than that in the molecular detection.

Acknowledgement The current research was financially supported by Tarbiat Modares University.

Author contributions Javid Sadraei contributed on proposal and sampling of this manuscript (25\%), Ehsan Shariat Bahadori contributed on analyzing of samples and experimentation (50\%) and Abdolhosein Dalimi contributed on data analyze and statistical survey $(25 \%)$.

\section{Compliance with ethical standards}

Conflict of interest The authors declare no conflict of interests.

Human and animal rights This study was approved by $\mathbf{5 2 / 3 5 9 5}$ number on 2015, Ethics committee, Tarbiat Modares University.

\section{References}

Ahmadpour GR et al (2017) Seroepidemiology of Toxoplasma gondii infection in pregnant women in west Iran: determined by ELISA and PCR analysis. J Parasit Dis 41:237-242. https://doi.org/10.1007/s12639-016-0784-3

Bastien $M$ et al (2018) High density of fox and cat faeces in kitchen gardens and resulting rodent exposure to Echinococcus multilocularis and Toxoplasma gondii. Folia Parasitol (Praha). https://doi.org/10.14411/fp.2018.002

Brouat $\mathrm{C}$ et al (2018) Seroprevalence of Toxoplasma gondii in commensal rodents sampled across Senegal. West Afr Parasite 25:32. https://doi.org/10.1051/parasite/2018036

Felin E, Nareaho A, Fredriksson-Ahomaa M (2017) Comparison of commercial ELISA tests for the detection of Toxoplasma antibodies in the meat juice of naturally infected pigs. Vet Parasitol 238:30-34. https://doi.org/10.1016/j.vetpar.2017. 03.012

Flegr J (2017) Predictors of Toxoplasma gondii infection in Czech and Slovak populations: the possible role of cat-related injuries and risky sexual behavior in the parasite transmission. Epidemiol Infect 145:1351-1362. https://doi.org/10.1017/S09502688 1700019X

Foronda P et al (2015) Serological survey of antibodies to Toxoplasma gondii and Coxiella burnetii in rodents in northwestern African islands (Canary Islands and Cape Verde). Onderstepoort J Vet Res 82:e1-e4. https://doi.org/10.4102 /ojvr.v82i1.899

Gennari SM et al (2015) Toxoplasma gondii antibodies in wild rodents and marsupials from the Atlantic Forest, state of Sao Paulo. Braz Rev Bras Parasitol Vet 24:379-382. https://doi.org/ 10.1590/S1984-29612015045

Hecker YP et al (2018) Evaluation of frequency of antibodies against Toxoplasma gondii, Neospora caninum and Sarcocystis spp. and transmission routes in sheep from Humid Pampa. Argent Acta Parasitol 63:416-421. https://doi.org/10.1515/ap-2018-0048

Hou ZF et al (2018) Prevalence, risk factors and genetic characterization of Toxoplasma gondii in sick pigs and stray cats in Jiangsu Province, Eastern China. Infect Genet Evol 60:17-25. https://doi.org/10.1016/j.meegid.2018.02.007

Jung BK, Song H, Lee SE, Kim MJ, Cho J, Shin EH, Chai JY (2017) Seroprevalence and risk factors of Toxoplasma gondii infection among cat sitters in Korea. Korean J Parasitol 55:203-206. https://doi.org/10.3347/kjp.2017.55.2.203

Khademvatan S, Saki J, Yousefi E, Abdizadeh R (2013) Detection and genotyping of Toxoplasma gondii strains isolated from birds in the southwest of Iran. Br Poult Sci 54:76-80

Liang Y, Chen J, Meng Y, Zou F, Hu J, Esch GW (2016) Occurrence and genetic characterization of Gra6 and Sag2 from Toxoplasma Gondii oocysts in cat feces, Kunming, China. Southeast Asian J Trop Med Public Health 47:1134-1142

Macaluso G et al (2018) Evaluation of a commercial enzyme-linked immunosorbent assay (ELISA) for detecting antibodies against Toxoplasma gondii from naturally and experimentally infected pigs. Infect Dis (Lond) 6:1-6. https://doi.org/10.1080/2374423 5.2018 .1490026 
Mikhail MW, Hasan AH, Ali Allam K, Mohammed NM (2017) Seroprevalence of Toxoplasma Gondii among commensal rodents from giza governorate. Egypt J Egypt Soc Parasitol 47:145-150

Mostafavi S, Jalali Monfared L (2012) Toxoplasmosis epidemiology in Iran: a systematic review. J Isfahan Med Sch 176:1-15

Must K, Hytonen MK, Orro T, Lohi H, Jokelainen P (2017) Toxoplasma gondii seroprevalence varies by cat breed. PLoS ONE 12:e0184659. https://doi.org/10.1371/journal.pone.0184659

Naghili B et al (2017) Comparison of IIF, ELISA and IgG avidity tests for the detection of anti-Toxoplasma antibodies in single serum sample from pregnant women. Infez Med 25:50-56

Normaznah Y, Azizah MA, Azuan MI, Latifah I, Rahmat S, Nasir MA (2015) Seroprevalence of Toxoplasma Gondii in rodents from various locations in Peninsular Malaysia. Southeast Asian J Trop Med Public Health 46:388-395

Oh $\mathrm{H}$ et al (2018) An outbreak of toxoplasmosis in squirrel monkeys (Saimiri sciureus) in South Korea. J Med Primatol. https://doi.org/10.1111/jmp.12344

Patel KK, Howe L, Heuer C, Asher GW, Wilson PR (2017) Evaluation of Western blot, ELISA and latex agglutination tests to detect Toxoplasma gondii serum antibodies in farmed red deer. Vet Parasitol 244:154-159. https://doi.org/10.1016 /j.vetpar.2017.08.003

Pena HFJ et al (2017) Fatal toxoplasmosis in an immunosuppressed domestic cat from Brazil caused by Toxoplasma gondii clonal type I. Rev Bras Parasitol Vet 26:177-184. https://doi.org/10.1590/S1984-29612017025

Pishkari S, Shojaee S, Keshavarz H, Salimi M, Mohebali M (2017) Evaluation of Toxoplasma gondii soluble, whole and excretory/ secretary antigens for diagnosis of toxoplasmosis by ELISA test. J Parasit Dis 41:289-291. https://doi.org/10.1007/s12639 -016-0794-1

Poulle ML, Forin-Wiart MA, Josse-Dupuis E, Villena I, Aubert D (2016) Detection of Toxoplasma gondii DNA by qPCR in the feces of a cat that recently ingested infected prey does not necessarily imply oocyst shedding. Parasite 23:29. https://doi.org/10.1051/parasite/2016029

Sharif M, Daryani A, Nasrolahei M, Ziapour SP (2009) Prevalence of Toxoplasma gondii antibodies in stray cats in Sari, northern Iran. Trop Anim Health Prod 41:183-187

Silva JCR et al (2017) Cat-rodent Toxoplasma gondii Type II-variant circulation and limited genetic diversity on the Island of Fernando de Noronha. Braz Parasit Vectors 10:220. https://doi.org/10.1186/s13071-017-2150-4
Simon JA et al (2017) Spatial distribution of soil contaminated with Toxoplasma gondii oocysts in relation to the distribution and use of domestic cat defecation sites on dairy farms. Int $\mathbf{J}$ Parasitol 47:357-367. https://doi.org/10.1016/j.ijpara.2017.01.004

Spada E et al (2012) Seroprevalence of feline immunodeficiency virus, feline leukaemia virus and Toxoplasma gondii in stray cat colonies in northern Italy and correlation with clinical and laboratory data. J Feline Med Surg 14:369-377. https://doi.org/10.1177/ $1098612 \times 12437352$

Teimouri A, Modarressi MH, Shojaee S, Mohebali M, Zouei N, Rezaian M, Keshavarz H (2018) Detection of toxoplasmaspecific immunoglobulin $\mathrm{G}$ in human sera: performance comparison of in house Dot-ELISA with ECLIA and ELISA. Eur J Clin Microbiol Infect Dis 37:1421-1429. https://doi.org/ 10.1007/s10096-018-3266-y

Verma SK, Knowles S, Cerqueira-Cezar CK, Kwok OC, Jiang T, Su C, Dubey JP (2018) An update on Toxoplasma gondii infections in northern sea otters (Enhydra lutris kenyoni) from Washington State, USA. Vet Parasitol. https://doi.org/10.1016/ j.vetpar.2018.05.011

Wang ZT, Verma SK, Dubey JP, Sibley LD (2017) The aromatic amino acid hydroxylase genes AAH1 and AAH2 in Toxoplasma gondii contribute to transmission in the cat. PLoS Pathog 13:e1006272. https://doi.org/10.1371/journal.ppat.1006272

Wang LJ et al (2018a) Protective immune response against Toxoplasma gondii elicited by a novel yeast-based vaccine with microneme protein 16. Vaccine 36:3943-3948. https://doi.org/ 10.1016/j.vaccine.2018.05.072

Wang T, Han Y, Pan Z, Wang H, Yuan M, Lin H (2018b) Seroprevalence of Toxoplasma gondii infection in blood donors in mainland China: a systematic review and meta-analysis. Parasite 25:36. https://doi.org/10.1051/parasite/2018037

Wang XL, Dong L, Zhang L, Lv Y, Li Q, Li H (2018c) Seroprevalence and genetic characterization of Toxoplasma gondii in naturally-infected synanthropic rodents in Yunnan Province, Southwestern China. J Parasitol. https://doi.org/ $10.1645 / 17-156$

Wang XL, Dong L, Zhang L, Lv Y, Li Q, Li HL (2018d) Seroprevalence and genetic characterization of Toxoplasma gondii in naturally infected synanthropic rodents in Yunnan Province, Southwestern China. J Parasitol 104:383-387. https://doi.org/10.1645/17-156

Publisher's Note Springer Nature remains neutral with regard to jurisdictional claims in published maps and institutional affiliations. 